\title{
THE USE OF CORTICOSTEROIDS IN THE TREATMENT OF ASTHMA AND RELATED CONDITIONS
}

\author{
By C. M. Fletcher, M.D., F.R.C.P. \\ Senior Lecturer in Medicine, Postgraduate Medical School
}

The Greek word ' asthma' means no more than ' a hard-drawn or gasping breath.' It may be applied to the dyspnoea of left ventricular failure, but is more usually taken to indicate bronchial asthma. It is with this sort of asthma that this article is concerned, and for this purpose asthma may be defined as dyspnoea due to generalized bronchiolar obstruction characterized clinically by wheezing respiration. It will be assumed that the diagnosis has been confirmed by the usual investigations, thereby excluding wheezing due to localized bronchial obstruction.

\section{Theoretical Considerations}

Asthma is generally regarded as belonging to the group of allergic or hypersensitivity reactions and is thought to be due to contraction of bronchiolar muscles in response to histamine liberated as a result of local antigen-antibody reactions. Mucosal oedema and hyperaemia and secretion of viscid mucus add to the bronchiolar obstruction. The promptness of the response of an asthmatic to an inhaled allergen is such that the asthmatic attack must be of the immediate rather than the delayed type of hypersensitivity reaction. Although cortisone inhibits the delayed type of sensitivity reaction in the skin (Long and Miles, 1950), its effect upon the immediate type of skin reaction to injected allergens in sensitive subjects has been reported to be insignificant (Feinberg et al., I95I ; Cook et al., 195 I; Pickering, 1952; Lovell et al., 1953). More recently, however, Holti (1956) has shown that cortisone does reduce the skin reaction to injected histamine and Herxheimer (1954) has shown that the amount of an inhaled allergen necessary to cause an attack of asthma in sensitive subjects is considerably increased when they are under cortisone treatment. There is no convincing demonstration of an impairment of adrenal function in allergic subjects during attacks of asthma (Siegel et al., 1956), so that there is no reason to suppose that the use of these drugs in asthma may be regarded as replacement therapy; entirely un- $\frac{\vec{b}}{2}$ physiological doses may be needed to produce an effect.

\section{Clinical Reports}

The literature on the treatment of asthma $\stackrel{\omega}{\circ}$ abounds with claims of success for innumerable $\circ$ methods which have later fallen into disuse after initial enthusiasm has worn off, or when control $\vec{c}$ trials have shown them to be useless. This is partly because of the profound importance of psycho- $D$ logical factors in inducing or relieving asthma ang $\overrightarrow{0}$ also because of the unpredictable course of th untreated disease. It is therefore necessary to extremely cautious about accepting claims for the value of corticosteroids which, when they were first introduced, were hailed with uncritical enthusiasm as a cure for nearly all the ills to which $\mathbb{D}$ mankind is heir and, more especially, as the solu- $\vec{F}$ tion to all the allergist's problems. Early reports on the use of these drugs in asthma were nearly all enthusiastic, but quite uncontrolled. The untoward side-effects and expense of prolonged administration were at first the only grounds for 3 . hesitation in accepting them as the treatment of $\dot{0}$ choice in asthma. Subsequently, controlled trials, almost all carried out in Great Britain, have shown 8 that the true place of corticosteroids in the treat- 3 ment of asthma is limited. Since the effect of these $\mathrm{O}$ drugs has been shown to be very different in acute $D$ attacks, in persistent asthma, and in asthma associated with other pulmonary diseases, the use of the drugs in these three types of case must be o considered separately.

\section{Acute Asthmatic Attacks and Status Asthmaticus}

The early uncontrolled claims of the effective- $c$ ness of corticosteroids in acute asthma (reviewed $\stackrel{\mathbb{D}}{\complement}$ by Brown, 1952) have been substantiated in this $\stackrel{?}{?}$ country by controlled trials of ACTH (Ball, 1954) 0 and of cortisone (M.R.C., 1956b). The latter trial was carried out on 32 cases in status asthmaticus 
M.R.C. TRIAL OF CORTISONE IN STATUS ASTHMATICUS

$\%$ of cases able to get up without audible wheeze

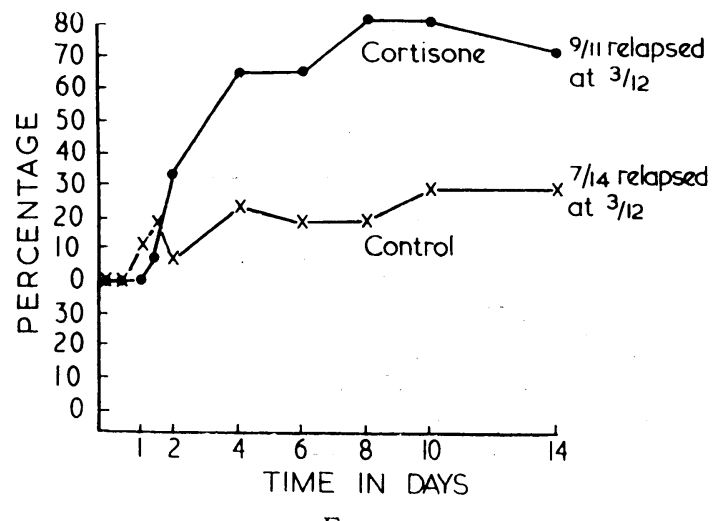

FI(:. I

that had failed to respond during 24 hours to routine anti-spasmodic treatment. Fifteen cases were given cortisone $(300 \mathrm{mg}$. on the first day with gradual reduction in dosage over Io days) and 17 were given undistinguishable control tablets. The results in terms of clinical assessment of virtual freedom from asthma are summarized in Fig. I. There is a highly significant difference in the response to the cortisone and control tablets. 'This difference only appears after two days and only becomes significant after four days. A similar delay in response to ACTH was reported by Ball and many other authors. In the M.R.C. trial there were two failures or withdrawals from the cortisone group. One was a woman with mitral stenosis who went into heart failure and died three months later, and the other was a man with an overwhelming bronchial infection who died on the fourth day. On the other hand, five failures in the control group all responded to corticosteroids on removal from the trial. Follow-up of these patients after the trial showed no evidence that the period of treatment had lessened the liability to further attacks of asthma and this conclusion is in agreement with all other reports.

Cases of acute asthma who fail to respond to corticosteroids fall into three groups. First, there are those in whom the side-effects of the corticosteroids prevent persistence with the treatment. Chief among these side-effects in short courses is fluid retention in cases complicated by heart failure. It may be possible to use prednisolone in these cases. A rare complication of ACTH therapy is an allergic or anaphylactic reaction to the drug which may be fatal (Levin, 1955; Bloom and Wolff, 1954; Swift, r 954; Serafini and di Nardo, 1955): Because of this possibility and the lack of any clear evidence that ACTH is superior to the other corticosteroids, I consider that it should only be tried when other corticosteroids have failed to produce a response. Next there are those cases in whom bronchial infection contributes to the obstruction. Whenever there is evidence of such infection appropriate antibacterial drugs must be given together with the corticosteroid. Lastly, there are those in which there is no clear explanation. Fatal cases of simple asthma are found at post-mortem to have bronchioles plugged by secretion and in some cases there may apparently be desquamation of ciliated epithelium (Earle, I953). It is not surprising that the bronchial obstruction is irreversible once this condition has become established (Aber et al., I954). The delay in the response to corticosteroids may also be explained in part by the time taken for these viscid secretions to be evacuated. For this reason delay in starting treatment with corticosteroids in severe acute asthma may be dangerous.

\section{Maintenance Treatment of Chronic Asthma}

Although reports of uncontrolled trials on the use of corticosteroids in maintenance treatment of chronic asthma have been rather less enthusiastic than reports on its use in acute asthma, they are nearly all extremely favourable. Table I summarizes the results obtained in a number of these reports. It is impossible to make strict comparisons between the varying methods of assessment used in these papers, but they agree that the drugs are beneficial in all but a small proportion of cases. Savidge and Brockbank (1954a) were less enthusiastic, though still favourable, as the result of a controlled trial in which 13 patients with persistent asthma were given oral cortisone and I4 similar patients were given a placebo for periods ranging from four to 80 weeks. 'They found that six out of the 13 cortisone treated cases derived significant benefit, but only one of the I 4 control cases derived equal benefit. 'They concluded that some cases of chronic asthma could be controlled by moderate doses of cortisone. However, their comparison may be criticized on the grounds that in some of the cases the nature of the treatment was known to the authors and the duration of treatment was not comparable in the two groups, being nearly twice as long in the cortisone as in the control groups. The Medical Research Council's trial (1956a) was a fully controlled 'double blind ' trial. Ninety-six patients from six centres between the ages of 14 and 60 with asthma of at least three months' duration and without severe broncho-pulmonary infection were given either cortisone or dummy tablets. The dose of cortisone (or placebo) started at $300 \mathrm{mg}$., falling to $100 \mathrm{mg}$. at the end of a week, and thereafter 


\section{M.R.C. TRIAL OF CORTISONE IN CHRONIC ASTHMA}

\section{$\%$ of cases free from Rhonchi (defaulters included in total)}

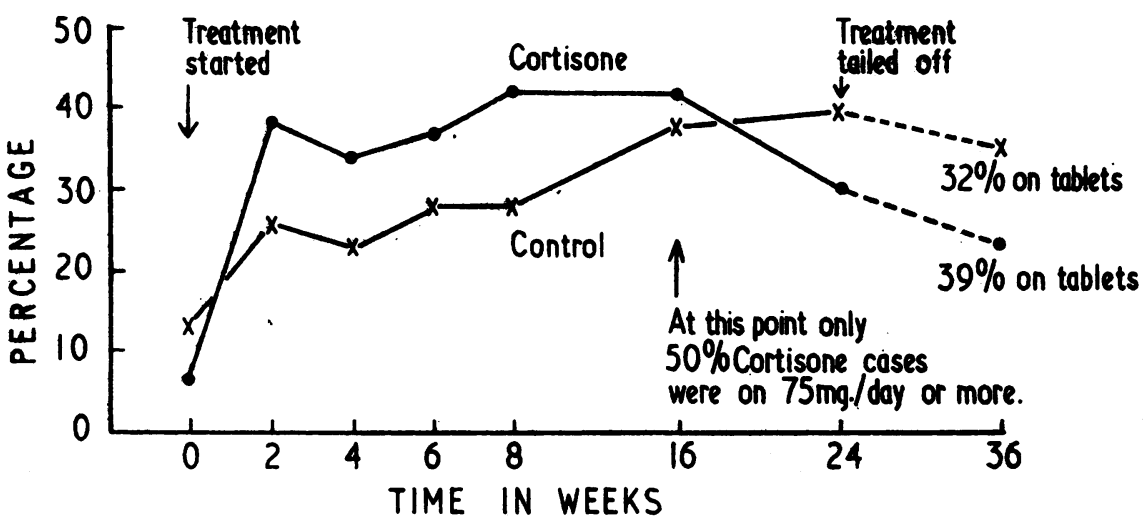

FiG. 2

dosage was adjusted by individual physicians, according to their assessment of the patient's needs. After 24 weeks the physicians were instructed to attempt to withdraw the tablets from those patients who could manage without them and the final assessment was made 36 weeks after the start of the trial. Unfortunately, assessment was purely clinical and no lung function tests were used. The most objective means of assessment was by the severity of rhonchi on auscultation and the results obtained by this method are summarized graphically in Fig. 2. The cortisone group showed significantly greater benefit than the control group from the second to the eighth week, but by the sixteenth week this difference had disappeared, and during the last 20 weeks of the trial the cortisone group were, if anything, less well off than the controls. (This may have been accounted for by the fact that some of the severer cases had been removed from the control group and transferred to corticosteroid therapy.) During the treatment period nine cortisone cases were withdrawn, five because of incidental illnesses, four of which (two psychoneuroses, one duodenal ulcer and one tuberculous kidney) may have been exacerbated by the cortisone. Two were withdrawn because of status asthmaticus and two defaulted. Ten control cases were withdrawn, five by default and five because of status asthmaticus. The conclusion is that cortisone is only of short-term benefit. The steady improvement of the control cases is notable and the fact that withdrawal of the control tablets was apparently as difficult as withdrawal of cortisone shows the powerful effect of suggestion on both patients and doctors. Fig. 3 shows that the exercise tolerance reported by the patients suggested a greater difference between treated and control groups than did the objective $\stackrel{\omega}{\odot}$ assessment. This is perhaps attributable to theo psychological effect of cortisone. However, the effects on capacity for work were very little dif- $\bar{c}$ ferent in the two groups, nor was there any difference in the need for other treatment in the two groups. All but five cortisone and four contro $\overrightarrow{k 0}$ cases received other forms of anti-spasmodies. throughout the trial.

The results of this trial have been described some detail because of the very real doubt they throw upon the value of maintenance therapy by corticosteroids. They indicate the reality of tem- $\mathrm{Q}$ porary benefit, confined to the first two months of $\Rightarrow$ treatment, and they show how difficult it is to을 distinguish over longer periods between the benefits of cortisone and that of entirely ineffective tablets.

Treatment of Asthma Associated with Bronchitis and/or Emphysema

In most reports of the treatment of asthma by corticosteroids bronchial infection is said to abolish the benefits of the treatment (Schwartz, I951; Davies and Williams, 1955; Savidge and Brock-o bank, 1954). Benefit in cases of emphysema has been slight and where it has been claimed there is considerable doubt as to the differential diagnosis of the emphysema from simple asthma (Bicker-o man, Beck and Barach, 1955; Galdston et al., N I95I; Lukas, I95I). In a controlled trial on cases of bronchitis and emphysema during acute exacerbations of infection Felix-Davies and Westlake (1956) showed that ACTH had no effect on the rate of recovery of ventilatory capacity. Kennedy? (1954) found no significant effect of cortisone on 0 the ventilatory capacity of cases of pneumo-oํㅜㅇ coniosis with bronchospasm. 'The improvement in 
Reported Results of Corticosteroid Maintenance Therapy for Bronchial Asthma

\begin{tabular}{|c|c|c|c|c|c|c|}
\hline \multirow{2}{*}{ Author } & \multirow{2}{*}{ Drug } & \multirow{2}{*}{$\begin{array}{l}\text { No. of } \\
\text { Cases }\end{array}$} & \multicolumn{3}{|c|}{ Results per cent. } & \multirow{2}{*}{ Comment } \\
\hline & & & Good & Fair & Poor & \\
\hline $\begin{array}{l}\text { Six authors collected by Savidg } \\
\text { and Brockbank (1954) } \\
\text { Turiaf et al. (1954) } \\
\text { Kania and Schmidt (1954) }\end{array}$ & $\begin{array}{l}\text { Cortisone } \\
\text { Hydrocortisone } \\
\text { Cortisone }\end{array}$ & $\begin{array}{r}95 \\
52 \\
111\end{array}$ & $\begin{array}{l}73 \\
64 \\
84\end{array}$ & $\begin{array}{l}16 \\
31 \\
20\end{array}$ & $\begin{array}{r}\text { II } \\
5 \\
5\end{array}$ & $\begin{array}{l}\text { Some short courses } \\
\text { included }\end{array}$ \\
\hline Arbesman and Richards (1954) & Cortisone & 86 & 65 & 24 & 12 & Occasional ACTH \\
\hline Serafini and di Nardo (1955) & $\begin{array}{l}\text { ACTH, hydrocortisone or } \\
\text { prednisone }\end{array}$ & II 5 & 76 & 18 & 6 & $\begin{array}{l}\text { Some short courses } \\
\text { included }\end{array}$ \\
\hline Barach et al. (1955) & Prednisor & 30 & $\underbrace{57}$ & 40 & 3 & $\begin{array}{l}\text { Eighteen had failed } \\
\text { on cortisone }\end{array}$ \\
\hline Sheldon et al. (1955) & Prednisone & $5 \mathrm{I}$ & & & 2 & Eleven had failed \\
\hline Taub et al. (1956) & Prednisone & I 53 & 30 & 65 & 5 & Some short courses \\
\hline Walton ( 1956 ) & $\begin{array}{l}\text { ACTH, cortisone or } \\
\text { hydrocortisone }\end{array}$ & I 53 & 48 & 50 & 2 & $\begin{array}{l}\text { Five failed cases } \\
\text { were all fatal }\end{array}$ \\
\hline
\end{tabular}

dyspnoea presumably depends upon whether it is predominantly due to reversible bronchial obstruction or to irreversible pulmonary damage.

\section{Side-efiects}

The undesirable side-effects of corticosteroids in asthma are the same as those encountered in other diseases (Bickerman and Barach, I954; Burrage et al., 1955; Irwin et al., 1954; Jenkins, 1955; Wang et al., 1955). They are considered elsewhere in this series of articles. The danger of an allergic reaction to $\mathrm{ACTH}$, to which reference has already been made, is probably greater in asthmatics than in other patients. Apart from this there have been a number of reports of deaths occurring during and after cortisone treatment of asthma. These have been attributed by some authors to hypo-adrenalism induced by cortisone (Savidge and Brockbank, 1954b), but the unpredictable course of asthma and the fact that fatal status asthmaticus may occur even under steroid treatment makes it difficult to accept this explanation. Henneman et al. (1955) investigated the effects of abrupt cessation of cortisone maintenance in 19 asthmatics. They observed no prompt return of asthma, though various other minor symptoms attributable to hypo-adrenalism occurred which were relieved by intravenous hydrocortisone.

\section{Recommendations}

From the evidence that has been presented it is necessary to attempt to derive some conclusions as to the indications for steroid treatment, the regime that should be adopted and the necessity for adjuvant therapy. It is clear from most reports that only a small minority of asthmatics require treatment by corticosteroids. Thus, over a period of nearly two years only 32 cases of status asthmaticus failing to respond to routine treatment were obtained from I 3 hospitals during the Medical Research Council trial of cortisone. Ball (1954) found that only 20 out of 132 and Johnson ( I954) only I4 out of 407 cases of asthma admitted to hospital required ACTH because of failure to respond to routine treatment. These reports were made at a time when the drugs were in relatively short supply and may not be generally applicable today. It must be remembered that status asthmaticus is a dangerous condition which may be rapidly fatal and that response to corticosteroids may be delayed for two days, so that it is risky to wait for as long as 24 hours to see whether they may be required. In severe asthma I recommend that if, after four hours in hospital, adrenalin aerosol and intravenous aminophyllin have not produced a significant improvement, corticosteroids should be given.

It is more difficult to assess the need for these drugs in asthmatic attacks, which, while not severe enough to be a threat to life or even to demand admission to hospital, are nevertheless severely disabling. The first essential in such cases is to ensure full investigation to discover and remove possible environmental causes for the attack, whether psychological or allergic, and then to ensure that adequate anti-spasmodic therapy is being given. Some cases that are quite resistant to ephedrine may obtain relief from choline theophyllinate or to a combination of the two, and occasional cases are encountered who deny relief from a hand inhaler with adrenaline or isoprenaline, but who respond promptly when properly instructed in the use of the inhaler. If, despite all 
such methods, disabling asthma persists, then steroids should be tried.

Since these drugs are potentially dangerous, especially in chronic cases, it is essential to ensure that any apparent benefit is really due to the drug itself. It may be due simply to an increase in morale from the psychological stimulus given by the drug. This confusion may be avoided by making objective measurements of ventilatory capacity in every case treated. Measurement of the one-second forced expiratory volume $\left(\mathrm{FEV}_{\cdot \mathbf{1 . 0}_{0}}\right)$ (Gandevia and Hugh-Jones, I957) and of its proportional relationship to the vital capacity is simple and provides a sensitive index of changes in ventilatory capacity. If a significant increase of ventilatory capacity occurs when steroids are started, it may still not be due to the drug itself, but to the patient's knowledge of the reputed effects of cortisone. This confusion may be avoided by starting the drug without telling the patient what it is and without any claims as to its likely benefit. Substitution of indistinguishable dummy tablets with repeat testing of the ventilatory capacity may show whether the effect is psychological or pharmacological in doubtful cases. If dummy tablets are given and the patient thinks they are cortisone (or a similar drug), steps must be taken to ensure that any other doctor called to treat the patient in an exacerbation will know that the tablets are dummies. Lastly, when benefit undoubtedly due to the corticosteroids has been conferred, every effort should be made to limit the duration of treatment or, if a maintenance dose is essential to keep it as low as possible, so that full dosage may be kept in reserve for acute and dangerous exacerbations.

The danger of extension of infection occurring without overt symptoms under cover of cortisone must always be kept in mind, more especially when, as in asthma, exacerbations may be associated with bronchopulmonary infections. A chest radiograph will presumably always have been taken before treatment is started. It should be repeated whenever a fresh course is begun and at regular intervals during maintenance therapy because of the danger of rapidly progressive tuberculosis. If there is any evidence of infection, either radiological or clinical, appropriate antibacterial drugs must be given promptly.

There is little doubt that oral prednisolone is the drug of choice (Barach et al., 1955; Jenkins, 1955; Sheldon et al., 1955), although in an acute emergency it may be preceded by intravenous hydrocortisone to obtain a more rapid response. There are those who prefer to use intravenous ACTH on the grounds that the natural steroids produced by the adrenal glands may be more effective than any single synthetic drug, but there is no clear evidence in support of this. There are certainly some cases which appear to respond tê? $\mathrm{ACTH}$ after having failed on cortisone, but the reverse occurs equally frequently (Arbesman andz Richards, I954; Bickerman and Barach, 1954 : Serafini and di Nardo, 1955). There are others. who like to combine ACTH with prednisolone or cortisone to avoid the atrophic effect of these drugs on the adrenal cortex (Arbesman and? Richards, 1954; Salassa et al., 1953; Taub et al., $\frac{\overline{\bar{N}}}{\overline{2}}$ 1956). This is rather an elaborate way of avoiding $\vec{\sigma}_{\overparen{\sigma}}$ a risk which is only encountered if the patient 0 abruptly discontinues taking the drug, which needकs never happen, and is, in any case, of doubtful $\vec{\circ}$ importance (Henneman et al., r955). Whenevertreatment is started it is best to begin with a $\vec{\omega}$ large dose and then to reduce it over several days: I $5 \mathrm{mg}$. of prednisolone may be given six-hourly at first and each dose may then be reduced by $5 \mathrm{mg}$. every other day until $5 \mathrm{mg}$. are being given + six-hourly. Thereafter the dose should be moree slowly reduced to find the minimum required for ${ }_{\omega}^{N}$ relief of symptoms, and with the firm intention of $\frac{\omega}{\circ}$ discontinuing the drug if at all possible after noto more than three months, even though repeated courses may often be necessary in some cases.

\section{BIBLIOGRAPHY}

ABER, G. M., CHANDLER, G. N., and HARTFALL, S.g. (1954), Brit. med. $\mathcal{F}$., i, I.

ARBESMAN, C. E., and RICHARDS, N. B. (1954), F. Allerg 25, 306 .

BALL, K. (1954), Lancet, i, 1 I62.

BARACH A. L, BICKERI Dis. Chest, 27, 5 I 5.

BICKERMAN, H. A., and BARACH, A. L. (I954), f. Allergy' 25, 312 .

BICKERMAN, H. A., BECK, (;. S., and BARACH, A. L. (I955), F. chron. Dis., 2, 247

BLOOM, A., and WOLFF, F. (1954), Brit. med. f., ii, 1354.

BROWN, E. A. (1952), Ann. Allergy, 10, 356, 496.

BURRAGE, W. S., RITCHIE, W. B., MANSFIELD, H. C., IRWIN, J. W., and RUSSFIELD, A. B. (1955), Ann. intern. Med., 43, roor.

('OOKE, R. A., SHERMAN, W. B., MENZEL, A. E. O., CHAPIN, H. B., HOWELL, C. M., SCOTT, R., B., MYERS,'O P. A., and DOWNING, L. M. (I95I), .7. Allergy, 22, 2 I I.

DAVIES, B. M., and WILliAMS, D. A. (1955), Brit. med. $\Varangle ., \bar{\sigma}$ ii, 293 .

EARLE, B. V. (1953), Thorax, 8, 195.

FEINBERG, S. M., DANNEBERG, 'T. P., and MALKIEL, S. O (1951), $\dot{f}$. Allergy, 22, 195 .

FELIX-DAVIES, D., and WES'TLAKE, E. K. (1956), Brit. med. F., ii, 780 .

(;ALDSTON, M., WEISENFELD, S. BENAMIN, B and ROSENBLEUTH, M. B. (1951), Amer. F. Med., ro, if8. and

(iANDEVIA, B., and HUGH-JONES, P. (1957), Thorax, in the press.

HENNEMAN, P. H., WANG, D. M. K., IRWIN, J. W., and $\mathcal{O}$

BURRAGE, W. S. (1955): '尹. Amer. med. Ass., r58, 384 ., and 0

HERXHEIMER, H. (I954), Brit. med. F., i, 184.
HOLTI, G. (1956), Clin. Sci., I5, I

IRWIN, J. W., HENNEMAN, P. H., WANG, D. M. K., and

BURRAGE, W. S. (1954), $\mathscr{f}$. Allergy, 25, 201. ${ }^{\circ}$.

JENKINS, C. M. (1955), Ann. Allergy, 13, 700.

JOHNSON, E. H. (1954), Wis. med. F., 53, 537. JOHNSON, E. H. (I954), Wis. med. F., 53, 537.
KANIA, E., and SCHMIDT, P. (1954), Munch. met. Wschr., 96,
759.

KENNEDY, M. C. S. (1954), Lancet, i, 77.

LEVIN, S. J. (1955), Pediatrics, 16, $4 \mathrm{I} 6$.

LONG, D. A., and MILES, A. A. (I950), Lancet, i, 492.

Bibliography continued on page 321 . 
in the blood has proved difficult because of the large amount of plasma required for estimations, but the method of Porter and Silber has become established.

Important progress in the scientific knowledge of cortisone metabolism has been made. It has been found that there is a diurnal variation in the level of blood hydrocortisone throughout the day in normal subjects. The mean value is high at 8 a.m., though in some people this is delayed till ro a.m., and falls during the next four hours. After a short rise it falls again and is low between 4 p.m. and 6 p.m. Studies done throughout the night have shown a low level at 3 a.m., followed by a rise to the morning peak.

Investigations on rheumatoid patients have shown that the blood hydrocortisone is high, but that there are greater fluctuations throughout the day than in normal subjects.

Work on the physiological dispositions and metabolic fate of hydrocortisone in man have been carried out following intravenous infusion. In normal subjects the half life in plasma averaged I.9 hours. Following the infusion of tracer quantities of hydrocortisone -4-C I4 metabolites appears in the plasma in substantial quantity in two hours. Normal subjects excrete over 90 per cent. as urinary metabolites in 72 hours. Liver disease delays the excretion of hydrocortisone.

\section{The Future}

As the recent advances in the estimation of blood hydrocortisone levels continue it should soon be possible to adjust the dosage of the cortisones by scientific calculation instead of by balancing clinical improvement against side effects.

However, in spite of the somewhat crude regime which has, of necessity, ruled the dosage of cor- tisone and its analogues since their introduction in r 948 , a large number of patients who had failed to respond to other treatment and who were crippled with rheumatoid arthritis have been relieved of pain and enabled to return to work.

\section{BIBLIOGRAPHY}

ALBRIGH'T, F. (1942), The Harry Lectures, Lancaster, Pa. The Science Printing Company, p. r 22.

APPLEBY, J. I., GIBSON, G., NORYMBERSKI, J. K., and STUBBS, R. D. (I955), Biochem. F., 60, 453.

BOLAND, E. W. (1950), Ann. rheum. Dis., 9, I.

BLACK, R. L., YIELDING, K. L., and BUNIM, J. J. (1957), F. chron. Dis., 5, $75 \mathrm{I}$.

BUNIM, J. J., ZIFF, M., and McEWEN, C. (1955), Amer. F. Med., 18, No. $1,27$.

COPEMAN, W. S. C., SAVAGE, O., BISHOP, P. M. F., DODDS, E. C., KELLIE, A. E., STEWAR'T, J. W., GLYNN, J. H. H., HENLY, A. A., and TWEED, J. M. (1952), Brit. med. F., i, 397.

COPEMAN, W. S. C., SAVAGE, O., DODDS, E. C., GLYNN, J. H. H., and FEARNLEY, M. E. (1954), Ibid., i, I I09.

COSTE, F., CAYLA, J., and DELBARRE, F. (1953), 'Cortisone et Corticostimuline (ACTH) en rhumatologie.' Masson, Paris.

EMPIRE RHEUMATISM COUNCIL TRIAL (1957), Ann. rheum. Dis., 16, No. 3, 277.

FEARNLEY, G. R., BALMFORTH, G. V., and BLATCHLEY, R. (1957), Brit. med. F., ii, 1263.

FISCHER, F., and BROCHNER-MORTENSEN, K. (I953), Ugeskr. Laeg., $115,203$.

GRAY, S. J., BENSON, J. A., REIFENSTEIN, R. W., and SPIRO, H. M. (1951), Ұ. Amer. med. Ass., 147, 1529.

GRAY, S. J., BENSON, J. A., Jr., SPIRO, H. M., and RÉIFENSTEIN, R. W. (I95 I), Gastroenterology, 19, 658.

HENCH, P. S., KENDALL, E. C., SLOCUMB, C. H., and POLLEY, H. F. (1949), Proc. Mayo Clin., 24, I8r.

HOLLANDER, J. L., BROWN, E. M., Jr., JESSAR, R. A., and BROWN, C. Y. (I95 I), F. Amer. med. Ass., I629.

ILLINGWORTH, R. S., LORBER, J., HOLT, K. S., RENDLESHORT, J., JOWET'T, G. H., and GIBSON, W. M. (1957), Lancet, ii, 653 .

MEDICAL RESEARCH COUNCIL AND NUFFIELD FOL YDATION (1954), ' Report of Joint Committee,' Brit. med. F., i, 1223 .

MEDICAL RESEARCH COUNCIL AND NUFFIELD FOL NDATION (1957), Ibid., ii, 199.

POPERT, A. J., and DAVIS, P. S. (1958), Lancet, i, 2 I.

PORTER, C. S., and SILBER, R. H. (1950), f. biol. Chem., 185, $20 \mathrm{I}$.

SAVAGE, O., DAVIS, P., CHAPMAN, L., POPERT, A. J., ROBERTSON, J. D., and COPEMAN, W. S. C.' (1957), Brit. med. F., ii, 1258 .

WARD, L. E., POOLEY, H. F., SLOCUMB, C. H., and HENCH, P. S. (1953), F. Amer. med. Ass., 152, i19.

WEST, H. F. (1957), Ann. rheum. Dis., 16, 322.

Bibliography continued from page 314-C. M. Fletcher, M.D., F.R.C.P.

LOVELL, R. R. H. GOODMAN, H. C., HUDSON, B. ARMíTAGE, P., and PICKERING, G. W. (I953), Clin. Sci., 12, 41 .

LUKAS, D. S. (1951), Amer. Rev. Tuberc., 64, 279.

MEDICAL RESEARCH COUNCIL (1956a), Lancet, ii, 798; (1956b), Ibid., ii, 803 .

PICKERING, G. W. (1952), Brit. med. F., i, 1207.

SALASSA, R. M., BENNETT, W. A., KEATING, F. R., and SPRAGUE, R. G. (1953), Ұ. Amer. med. Ass., 152, 1509.

SA'VIDGE, R. S., and BROCKBANK, W. (1954a), Lancet, ii, 889; (1954b), Ibid., ii, 893 .

SCHWARTZ, E. (1951), ₹. Amer. med. Ass., 147, 1734.

SERAFINI, U., and DI NARDO, U. (1955), Act. allerg. (Kbh.), 9, 24 I.
SHELDON, J, MCLEAN, J. A, and MATHEWS, K. P. (1955), f. Mich. med. Soc., 54, 1081.

SIEGEL, S. C., ELY, R. S., BIRNBERG, V., and KELLY, V. C. (1956), ₹. Allergy, 27, 504.

SWIFT, S. (1954), Ann. Allergy, 12, 172.

TAUB, S. J., KAPLAN, M. A., and AARONSON, A. L. (1956), 7. Allergy, 27, 5 I4

TURIAF, J., MARLAND, P., and JEANJEAN, Y. (1954), Bull. Soc. méd. Hôp. Paris, 7o, 966.

WALTON, C. H. A. (1956), Canad. med. Ass. F., 75, 557.

WANG, D. M. K., BURRAGE, W. S., IRWIN, J. W., and ARONOW, S. (1955), $\mathcal{F}$. Allergy, 26, 448. 